\title{
Escolas Técnicas do SUS (ETSUS) no Brasil: regulação da integração ensino serviço e sustentabilidade administrativa
}

\author{
Vocational health schools (ETSUS) in Brazil: regulation \\ of the integration of teaching-service-administrative \\ sustainability of ETSUS
}

Fabiano Tonaco Borges ${ }^{1}$

Cléa Adas Saliba Garbin ${ }^{2}$

Carlos Eduardo Siqueira ${ }^{3}$

Artênio José Ísper Garbin ${ }^{2}$

Najara Barbosa da Rocha ${ }^{2}$

Luíz Fernando Lolli ${ }^{2}$

Suzely Adas Saliba Moimaz ${ }^{2}$
${ }^{1}$ Escola de Saúde Pública do Estado de Mato Grosso. Av. Adauto Botelho 552,

Coophema. 78085-200 Cuiabá MT.

fabianotonaco@yahoo.com.br ${ }^{2}$ Departamento de Odontologia Infantil e Social, Faculdade de Odontologia de Araçatuba, Universidade Estadual Paulista Júlio de Mesquita Filho.

${ }^{3}$ Department of Community Health and Sustainability, School Of Health And Environment, University of Massachusetts at Lowell.
Abstract The scope of this study was to discuss the administrative sustainability of Brazil's Vocational Health Schools (ETSUS) based on the principle of teaching and service integration, which brings a new dimension to healthcare work as yet unregulated by Brazilian public administration. It was a qualitative study using case study methodology. The research involved a semi-structured questionnaire given to ETSUS managers addressing institutional, administrative, and work management aspects. The sample was composed of 6 ETSUS that belong to the Network of Vocational Health Schools (RET-SUS). The ETSUS showed centralized planning and management, and decentralized implementation of their core activities. The majority did not have administrative autonomy and relied heavily on funding from the federal government. According to ETSUS managers, the lack of regulation of teaching activities by civil servants weakens the management of ETSUS. The ETSUS have managerial problems related to teaching-service integration, which has to be regulated in order to guarantee the sustainability of these schools and avoid conflicts with Brazilian legislation.

Key words Professional education, Human resources, Schools for public health professionals, Policy, planning and management in health, Public administration
Resumo O objetivo deste artigo foi discutir a sustentabilidade administrativa das Escolas Técnicas do SUS (ETSUS) a partir do principio da integração ensino serviço, que traz uma nova dimensão do trabalho na saúde ainda não regulada pela administração pública brasileira. Trata-se de uma pesquisa qualitativa, por meio de um estudo de caso. A pesquisa foi realizada por meio de questionário semiestruturado junto aos gestores das ETSUS, abordando aspectos institucionais, administrativos e de gestão do trabalho. O universo amostral foi de 6 ETSUS pertencentes à Rede de Escolas Técnicas do SUS (RET-SUS). As ETSUS apresentaram gestão e planejamento centralizados e execução descentralizada de sua atividade fim, em sua maioria sem autonomia administrativa e altamente dependente de financiamento do governo federal. Segundo os gestores das escolas, a falta de regulação da atividade docente por servidor público fragiliza a gestão das ETSUS. Estas instituições apresentam problemas de gestão relacionados à integração ensino serviço, que precisa ser regulamentada para conferir sustentabilidade às escolas e evitar contradições com a legislação brasileira.

Palavras-chave Educação profissionalizante, Recursos humanos, Escolas para profissionais de saúde, Políticas, Planejamento e Administração em Saúde, Administração pública 


\section{Introdução}

$\mathrm{Na}$ América Latina os sistemas de saúde lidam com a segmentação e a descoordenação das políticas públicas no desenvolvimento de suas reformas setoriais, sob o regime de arroxo fiscal e pouca capacidade redistributiva do gasto público em saúde ${ }^{1}$. O Sistema Único Saúde (SUS) não foge a esta regra, convivendo com um crônico subfinanciamento, submetido à supremacia de políticas neoliberais ao longo de sua história ${ }^{2-5}$. A contradição de uma macro-estrutura liberal na organização do sistema brasileiro e a luta por um modelo que persiga as necessidades de saúde da população carregam o movimento contrahegemônico da reforma sanitária de desafios ${ }^{6-9}$.

Nos países que buscam ampliar o acesso aos serviços de saúde por meio de uma ampla reforma na atenção primária como Austrália ${ }^{10}$, Venezuela $^{11}$, China ${ }^{12}$ e o próprio Brasil ${ }^{13}$, emergem amplas políticas de formação de recursos humanos nos serviços de saúde nas dimensões do ensino, gestão, atenção e controle social, atuando como mecanismos de transformação do modelo hegemônico, baseando-se na reflexão crítica sobre o trabalho em saúde ${ }^{14-17}$.

Nas últimas três décadas, o campo da saúde no Brasil desenvolveu espaços de produção de conhecimento na educação profissional que permitiram sistematizar as experiências acumuladas ao longo dos anos e avançar na conformação de alternativas pedagógicas adequadas às características do setor e às demandas originadas das políticas públicas para a área ${ }^{18}$. Este desenvolvimento faz parte da agenda do Movimento Latino Americano de Medicina Social, conhecido no Brasil como Saúde Coletiva, que tem na educação dos profissionais importante ferramenta para transformação dos referidos sistemas por seus trabalhadores ${ }^{19,20}$, influenciados pelo caráter reformador da educação ${ }^{21}$ e pelo empoderamento do espaço de trabalho da saúde ${ }^{22}$.

A integração do trabalho com a educação passou a ser para o SUS uma forma de superar a dívida do sistema educacional com seus profissionais, como também de melhorar a qualidade da assistência prestada à população. Desde a década de 60, desenvolveram-se as Escolas Técnicas e os Centros Formadores de Recursos Humanos do SUS (ETSUS) com a missão de formar e qualificar trabalhadores dos níveis básico e médio, que atuam ou irão atuar nos serviços públicos de saúde ${ }^{18,23,24}$. Atualmente são 36 escolas em todo o Brasil (Quadro 1) vinculadas ao SUS e responsáveis pela educação de cerca 480.857 trabalhadores dos serviços públicos de saúde nas três esferas de governo ${ }^{25-27}$.

O objetivo deste artigo foi discutir a sustentabilidade administrativa das ETSUS a partir do princípio da integração ensino serviço, que traz uma nova dimensão do trabalho na saúde ainda não regulada pela administração pública brasileira. Serão abordados inicialmente sua origem, conceito e política norteadora. Em seguida serão descritos os métodos utilizados para a realização da pesquisa e seus resultados. Finalizando, a discussão abordará os pontos sensíveis encontrados na gestão das ETSUS diante do SUS e dos limites da administração pública, apontando a regulação da atividade programática destas escolas como ponto central para sua sustentabilidade.

\section{Aproximação Histórica às ETSUS}

Na década de 70 no Brasil, os programas de expansão de cobertura (PEC) para as populações rurais e as campanhas de saúde pública proporcionaram a organização dos centros formadores de recursos humanos em saúde nas estruturas de suas respectivas secretarias estaduais de forma a qualificar pessoal com baixa escolarização no próprio serviço, quando ainda não havia a preocupação da habilitação profissional prévia para o trabalho na saúde $e^{4,18,23,28}$. A maioria das ETSUS foram criadas a partir da década de 80 com o objetivo primordial de promover a profissionalização dos trabalhadores de nível médio para o desenvolvimento das ações de saúde ${ }^{24,28,29}$. Convergindo com este movimento têm-se a luta dos trabalhadores da saúde por reconhecimento profissional e o movimento da reforma sanitária influenciando a organização das ETSUS no país ${ }^{30,31}$. Além disso, o complexo setor saúde e um contingente de técnicos já empregados no setor sem formação adequada justificariam a criação de escolas específicas para a formação de seus recursos humanos ${ }^{18,23}$. Durante a década de 90 , o papel das ETSUS se inscreveu no centro de três grandes processos em curso no estado brasileiro: a reforma do aparelho do estado, a reforma educacional e a reforma sanitária brasileira ${ }^{18}$.

O Programa de Formação em Larga Escala de Pessoal de Nível Médio e Elementar para os Serviços Básicos de Saúde (Larga Escala) desempenhou importante papel na formação dos trabalhadores de nível médio, lançando bases para a proposta da integração do ensino nos serviços públicos de saúde brasileiros, bem como contribuiu para a estruturação da política pedagógica das ETSUS. Este programa, desenvolvido na dé- 
Quadro 1. Centros Formadores e Escolas Técnicas do SUS-ETSUS ${ }^{13}$.

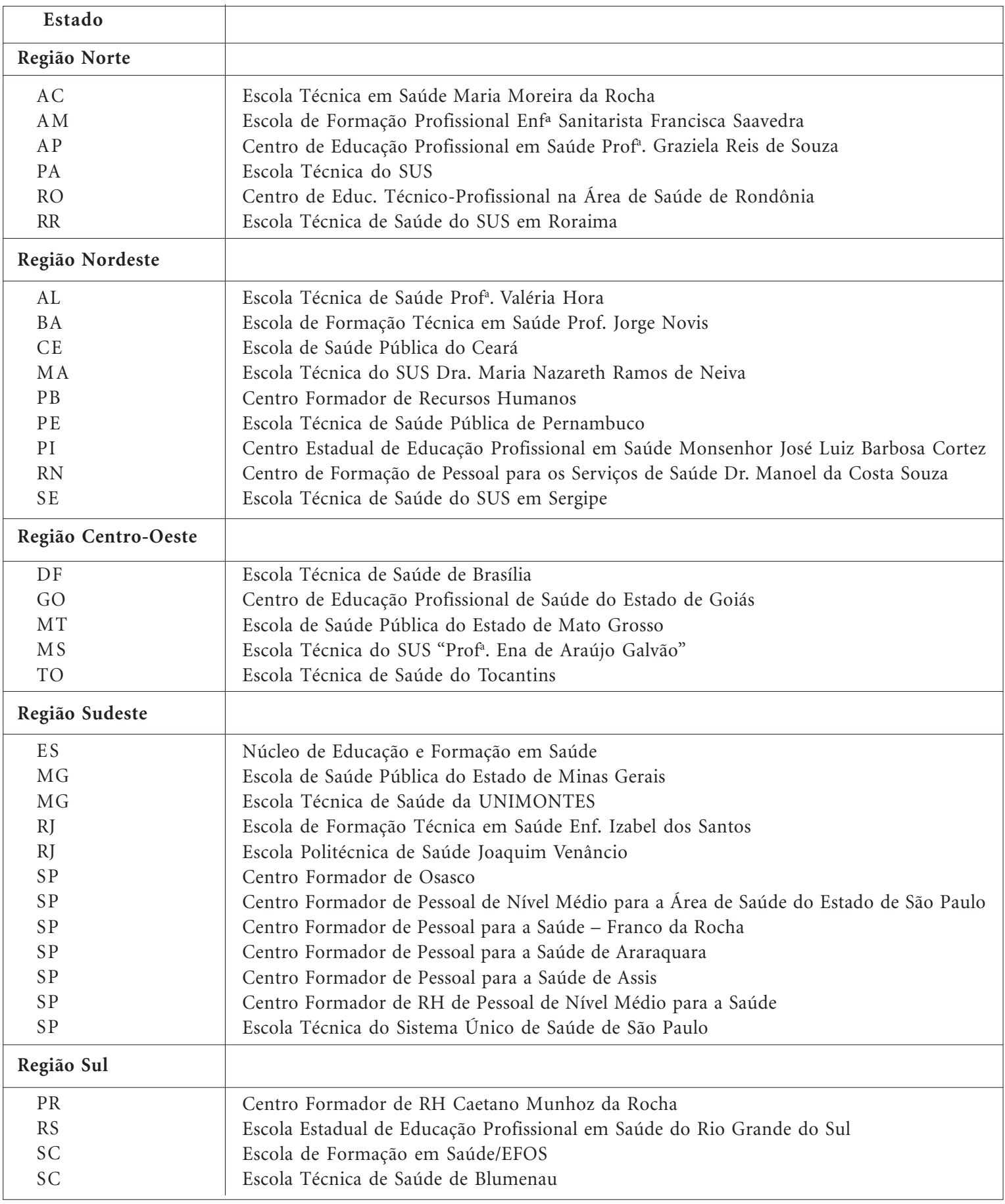

cada de 80 , teve o objetivo de formar cerca de 300 mil trabalhadores sem qualificação específica para o trabalho em saúde que desempenhavam as funções mais diversas, desde a administração de serviços gerais até processos assistenciais ${ }^{32}$. Representando à época cerca de $50 \%$ da força de trabalho empregada na saúde, milhares de servidores assumiram tarefas essenciais e complexas sem valorização social e institucional, nem identidade para incorporar-se às organizações profissionais, além de baixíssima inserção nos planos de carreira, cargos e salários de suas organizações ${ }^{30,32}$. O programa durou 19 anos (1981-1999) com quase 96 mil alunos qualificados - dos quais $60 \%$ 
a70\% profissionais da enfermagem - e outros três mil docentes formados, resultado de parceria entre o Ministério da Saúde brasileiro e a OPAS $^{31}$.

A experiência brasileira no Larga Escala serviu de paradigma na década 90 para o desenvolvimento, no eixo educacional, do Programa de Desenvolvimento de Recursos Humanos da Organização Pan Americana da Saúde (OPAS), vinculado às reformas setoriais da saúde na América Latina $^{32,33}$. Neste período, o Brasil recebeu financiamento para três projetos, dentre os quais o Programa de Profissionalização dos Trabalhadores da Área de Enfermagem (PROFAE), financiado pelo Banco Interamericano de Desenvolvimento (BID), em parceria com o Ministério da Saú$\mathrm{de}^{33}$. O PROFAE foi um passo adiante do Larga Escala, idealizado como dois olhares: um para os 270 mil trabalhadores de enfermagem que prestavam assistência a saúde sem qualificação adequada e outro para criar mecanismos de sustentabilidade para as ETSUS ${ }^{18,30}$. De 2000 a 2009 o PROFAE formou, segundo dados do Departamento de Gestão da Educação na Saúde do Ministério da Saúde, 319.518 trabalhadores de enfermagem $^{34}$, sendo o maior projeto de educação em saúde e capacitação técnica na história do Bra$\mathrm{sil}^{4}$. Verificou-se entre os egressos do PROFAE o aumento dos vínculos formais de trabalho, tanto entre os que estavam desempregados antes do curso quanto nos já empregados.

\section{As ETSUS como Escolas Função}

Como definiu a enfermeira Izabel Santos, precursora deste movimento no Brasil, as ETSUS são escolas-função ${ }^{30}$, escolas-flexíveis ${ }^{23}$, multiprofissionais, de caráter inclusivo, participativo e democrático. Como ferramentas de transformação propõem a reflexão do fazer no ambiente do trabalho, promovendo o aprendizado institucional. Elas atuam na formação de técnicos de vigilância em saúde, ambiental e sanitária, de técnicos de enfermagem, de saúde bucal, radiologia, reabilitação, patologia clínica, como também dos agentes de saúde indígena, entre outras categorias e níveis de formação. O público-alvo das ETSUS é composto por adultos provenientes das camadas populares, marginalizados pelo sistema formal de educação e desempenhando funções vitais nos serviços públicos de saúde.

As ETSUS estão organizadas na Rede de Escolas Técnicas do Sistema Único de Saúde (RETSUS) criada pelo Ministério da Saúde, Conselho Nacional de Secretários de Saúde (CONASS),
Conselho Nacional de Secretarias Municipais de Saúde (CONASEMS), e pela Organização PanAmericana de Saúde/BRASIL (OPAS) ${ }^{25,35}$. A RETSUS completou 10 anos de existência em 2010, atuando como órgão coordenador da formação profissionalizante no SUS com o objetivo de compartilhar informações, buscar soluções de problemas de interesse comum, difundir tecnologias e promover a articulação de instituições de educação profissional em todo país ${ }^{25,35}$, constituindo-se numa organização técnica e política das ETSUS.

Atualmente as ETSUS estão envolvidas no programa de Formação de Profissionais de Nível Médio para a Saúde (PROFAPS) com a meta de formar 260 mil trabalhadores até o final de 2011, num investimento previsto de R\$ 60 milhões $^{36}$. Outro programa em andamento é a formação Técnica dos Agentes Comunitários de Saúde (ACS), que contemplou com o itinerário inicial de 400 horas 153.435 alunos em todo Brasil desde 2004, segundo dados obtidos junto ao Departamento de Gestão da Educação na Saúde do Ministério da Saúde ${ }^{34}$. O alcance internacional das ETSUS foi dado com sua participação na formação de trabalhadores do sistema de saúde público do Haiti após o terremoto do início de $2010^{37}$.

\section{Projeto Político Pedagógico}

A integração ensino serviço emerge como proposta política e metodológica para a formação de trabalhadores sem qualificação ou formação específica. Trabalhadores edificam o saber entre si a partir de sua realidade nas dimensões do saber, do ser e do fazer. Norteando o projeto político pedagógico das ETSUS têm-se a concepção da educação politécnica que pressupõe o trabalho como instrumento educativo orientada pela práxis $^{38}$. Sob esta perspectiva a educação passa a permear o trabalho na saúde uma vez que um profissional ao ser qualificado por formação docente passa a formar seus colegas no próprio ambiente de trabalho, criando uma nova dinâmica na relação entre trabalhadores, e destes com os serviços de saúde e a comunidade, numa perspectiva transformadora.

As ETSUS se organizam pedagogicamente por meio da metodologia da Problematização, da Capacitação Pedagógica e do Sistema de Certificação por Competências. A Problematização constitui-se na metodologia do ensino, estudo e do trabalho para ser utilizada nos temas relacionados com a vida em sociedade ${ }^{39}$. A partir de um problema detectado na vida cotidiana a meto- 
dologia da Problematização volta-se para a realização do propósito maior que é preparar o estudante/ser humano para tomar consciencia de seu mundo e atuar intencionalmente para transformá- $l^{39}$. A capacitação pedagógica viabiliza a formação professor/trabalhador contextualizada em práticas sociais de saúde pautada na reflexão crítica voltada para a construção de competências profissionais referenciadas nestas práticas, em que o professor exerce, numa perspectiva de totalidade pessoal, as mediações possíveis da relação do aluno com o mundo ${ }^{40}$. Previamente a realização de um curso, aqueles trabalhadores que passaram a acumular a atividade docente, quer seja nos momentos de concentração para realização das atividades em classe de aula quer nos momentos de dispersão para a supervisão das atividades práticas, são capacitados pedagogicamente levando-se em consideração o contexto dos trabalhadores/alunos e dos serviços de saúde ${ }^{41}$. O sistema de certificação por competências busca prioritariamente reconhecer e valorizar a qualificação real do trabalhador, compreendida como um conjunto de competencias que vão além da dimensão cognitiva, constituindose mais no "saber-ser" do que no "saber-fazer" ${ }^{\prime 2,43}$.

A partir de 2004, a Política Nacional de Educação Permanente em Saúde (PNEPS) passa a guiar as ações da RET-SUS nos domínios administrativo, técnico e político. Educação Permanente em Saúde é definida como a aprendizagem no trabalho, onde o aprender e ensinar se incorporam ao cotidiano das organizações ${ }^{44,45}$. Em seu centro traz a integração ensino serviço como proposta metodológica para o desenvolvimento de competências para os serviços de saúde. Essa abordagem pode propiciar a democratização institucional e o desenvolvimento das capacidades de aprendizagem, da docência e do enfrentamento criativo das situações de saúde ${ }^{14}$. Cecílio ${ }^{46}$ definiu a EPS como um processo de sístole/diástole visando o envolvimento do maior número de trabalhadores nas discussões em seus locais de trabalho nos momentos de diástole ou dispersão, e grandes momentos de síntese, de reflexão compartilhada nos momentos de sístole ou concentração, constituindo-se em espaço privilegiado de observação da vida organizacional do SUS em toda sua diversidade e complexidade.

\section{Desafio}

O SUS constitui-se num sistema estatal isolado com grandes dissensos com as demais áreas da administração pública, principalmente o direito público, planejamento e fazenda, sem contar com a nova tecnocracia administrativa rigidamente normatizada ${ }^{6}$. O novo sistema de saúde herdou uma estrutura administrativa centralizadora do regime militar, adotando a Teoria Geral da Administração como guia no planejamento normativo; administração de recursos humanos, financeiros e materiais; e avaliação de resultados ${ }^{6}$. Por outro lado, os profissionais da saúde não foram deserdados da tradição liberal mantendo um alto grau de autonomia. Diante destes enunciados, as ETSUS procuram se consolidar num espaço tenso, desafiado pelo processo de descentralização dos serviços de saúde dos últimos 22 anos. Estas instituições utilizam a integração ensino serviço como instrumento não só pedagógico, mas de gestão, baseados no espaço do serviço e no "poder" do trabalhador da saúde. Contraditoriamente, as ETSUS desempenham um papel relevante na organização do trabalho na saúde no Brasil sem conseguir estabelecer uma relação sustentável do ponto de vista administrativo com seus professores, diante do princípio da integração ensino serviço, pela falta de subsídios legais para o pagamento de horaaula. Frequentemente há a interpretação, por órgãos de controle interno e externo da administração pública, de acumulo indevido de remuneração quando um servidor público no seu horário de trabalho acumula a função de docente recebendo por ela, colocando a integração ensino serviço à margem do processo legal. Esta distorção legal que atinge as ETSUS relaciona-se também aos municípios e aos Colegiados de Gestão Regional que são responsáveis pela condução da PNEPS regionalmente. A tese defendida neste estudo sustenta que as ETSUS postulam uma nova dimensão do espaço de trabalho nos serviços de saúde brasileiro à luz da integração ensino serviço, ainda não disciplinada pela administração pública, que comprometem a sustentabilidade gerencial destas instituições.

\section{Métodos}

No presente estudo utilizou-se como ferramenta metodológica o estudo de caso ${ }^{47}$ numa abordagem qualitativa do perfil administrativo das ETSUS. Minayo e Sanches ${ }^{48}$ subsidiam a abordagem metodológica deste estudo ao definir o papel do estudo qualitativo: A abordagem qualitativa realiza uma aproximação fundamental e de intimidade entre sujeito e objeto, uma vez que ambos 
são da mesma natureza: ela se envolve com empatia aos motivos, às intenções, aos projetos dos atores, a partir dos quais as ações, as estrutura se as relações tornam-se significativas.

Ao buscar conhecer aspectos gerenciais de instituições que usam o trabalho como metodologia de ensino nos serviços de saúde pública incluiu-se 6 escolas pertencentes à RET-SUS nas regiões Centro-Oeste (1), Nordeste (1), Sul (1) e Sudeste (3). Para a coleta de dados realizou-se inquérito com os gestores das ETSUS por meio de questionários semiestruturados enviados por e-mail. O questionário contém perguntas abertas e fechadas, divididas em três módulos conforme o Quadro 2, com campos para breve descrição pelo participante da pesquisa. A coleta de dados foi realizada entre setembro de 2010 e janeiro de 2011.

Todos os participantes no inquérito são gestores das ETSUS (diretores ou coordenadores) que respondem diretamente pela instituição. Esta pesquisa envolveu também levantamento bibliográfico de documentos oficiais do Ministério da Saúde, da revista da RET-SUS, da base de dados da biblioteca da Organização Pan Americana da Saúde (OPAS), da literatura oficial do SUS e de bases de artigos científicos nacionais e internacionais. No que concerne aos aspectos éticos, encaminhou-se aos entrevistados o termo de consentimento livre e esclarecido, por meio do qual os pesquisadores se colocaram à disposição para sanar quaisquer dúvidas a respeito de implicações éticas decorrentes desta pesquisa. Para salvaguardar o anonimato dos participantes, não foi citado neste artigo o estado ao qual cada ETSUS pertence. Este projeto foi aprovado pelo comitê de ética em pesquisa da Faculdade de Odontologia de Araçatuba (FOA) da Universidade Estadual Paulista "Júlio de Mesquita Filho"(UNESP).

\section{Resultados}

Numa primeira aproximação às escolas, este estudo discute aspectos institucionais. Todas são da administração direta ligada ao SUS, sendo cinco na esfera estadual e uma na municipal. As secretarias de saúde mantêm cinco das ETSUS pesquisadas, com uma gerenciada por um consórcio intermunicipal de saúde. A subordinação na estrutura organizacional da mantenedora transitou entre coordenadorias de recursos humanos, diretoria de ações de saúde, secretaria adjunta e gabinete do secretário; apenas uma não possui estrutura organizacional própria. Em relação à autonomia de gestão, cinco declararamse dependentes da mantenedora para firmar qualquer contrato, convênio, ou cooperação. Duas escolas analisadas possuem identidade jurídica própria. O Quadro 3 resume alguns dos aspectos institucionais da ETSUS.

Somente uma das instituições relatou dotação orçamentária própria e autonomia na ordenação de despesas; três reportaram problemas com a execução de recursos para suas atividades. A alocação anual de recursos não pareceu estável em três escolas e nas demais existe percentual préestabelecido do orçamento do ente federado responsável. Todas recebem transferências de recursos da União na modalidade fundo a fundo, condicionadas a pactuação de projetos, e por convênios com financiamento de órgãos internacionais como o Banco Interamericano de Desenvolvimento (BID) e o Banco Mundial, consignados pelo governo federal. Houve relatos de atraso na transferência de recursos, insuficiência dos mesmos, cortes, contingenciamentos, e falta de autonomia de gestão. As despesas relatadas cobrem pessoal, contratação de docentes externos (que não fazem parte do quadro de pessoal da mantenedora e/ou

Quadro 2. Principais Temas Abordados no Questionário.

\begin{tabular}{|l|l|}
\hline \multicolumn{1}{|c|}{ Categorias } & \multicolumn{1}{c|}{ Variáveis } \\
\hline Institucional & $\begin{array}{l}\text { Relação administrativa com o SUS; instrumentos legais de criação das escolas; } \\
\text { posicionamento organizacional; ente federado mantenedor. }\end{array}$ \\
\hline Administrativa & $\begin{array}{l}\text { Financiamento; capacidade de execução orçamentária dos recursos; relação } \\
\text { contratual com corpo docente; capacidade de execução dos projetos pactuados } \\
\text { pela PNEPS. }\end{array}$ \\
\hline Gestão do trabalho & $\begin{array}{l}\text { Planos de carreira e previsão da docência em serviço; existência de regulação por } \\
\text { leis, decretos ou portarias que disciplinem a atividade docente nos serviços de } \\
\text { saúde; percepção dos gestores a respeito da consonância das ETSUS com o } \\
\text { princípio da integração ensino serviço. }\end{array}$ \\
\hline
\end{tabular}


Quadro 3. Características Administrativas das ETSUS.

$\checkmark \quad$ Organização em rede com alta integração entre seus pares, com projeto político unificador e agenda comum perene.

$\checkmark \quad$ Atuam com ações em ampla escala envolvendo trabalhadores do SUS, bem como a sociedade civil organizada e movimentos sociais.

$\checkmark \quad$ Trabalham pela lógica de projetos, construídos e pactuados dentro do SUS.

$\checkmark$ Orçamento com certa volatilidade, altamente dependente de políticas do governo federal.

$\checkmark$ Gestão e planejamento centralizados.

$\checkmark$ Ações educacionais descentralizadas, adaptando-se fisicamente à realidade dos serviços que recebem os cursos.

$\checkmark$ Quadro de trabalhadores originalmente da mantenedora (a maioria de secretarias de saúde).

$\checkmark \quad$ Atuam sem quadro docente permanente, utilizando-se de força laboral dos serviços que recebem os cursos.

$\checkmark \quad$ Sem plano de carreira próprio, subsidiadas nos planos das mantenedoras (quando possuem).

$\checkmark \quad$ Possuem equipes de gestão das atividades educacionais, mas sem equipes de gestão do trabalho.

$\checkmark$ A seleção do corpo docente se dá por concurso público, licitações, indicação do serviço, notório saber e editais públicos.

$\checkmark \quad$ Sem uma política clara de gestão docente por meio da integração ensino serviço. O contrato entre as ETSUS e corpo docente é precário em sua maioria.

$\checkmark \quad$ Pouca autonomia administrativa e altamente dependente das mantenedoras, em que pese a disponibilidade de recursos específicos para suas ações.

Apresentam problemas de gestão que comprometem prazos e resultados.

da ETSUS), capacitação para seus trabalhadores, compra de material permanente e de consumo, contratação de serviços, produção de material didático e obras e reformas.

Em relação aos aspectos programáticos das ETSUS, a integração ensino serviço orienta a realização dos seus cursos, porém a instrumentalização legal desta atividade foi pouco citada. Duas escolas relataram utilizar decretos ou portarias para selecionarem professores e o mesmo número reportou celebrar contratos com docentes, onde o pagamento dos docentes se dá por hora-aula e hora-atividade ministradas. A precariedade dos vínculos é uma preocupação para todos os gestores entrevistados. Quatro dos seis gestores acreditam que a falta de uma regulamentação da atividade docente em serviço influencia negativamente a execução orçamentária das ETSUS. Apesar deste cenário, somente uma escola reportou sofrer ações trabalhistas e outra questionamentos por órgãos de controle externo (Tribunais de Contas, Auditorias e Controle Interno).

Quando questionados sobre a necessidade de planos de carreira específicos para as ETSUS os gestores foram unânimes em afirmar tal necessidade, mesmo nos casos onde o estado prevê a docência por servidores públicos. A exceção de uma, as escolas reportam a falta de harmonia entre a legislação que disciplina o regime jurídico único dos servidores públicos (formas de seleção, contratação, pagamento) e o princípio da integração ensino serviço, estabelecido pela política de educação permanente na saúde. Tal fato, para os gestores, traz danos à vocação das ETSUS de formar trabalhadores em serviço por meio de seus pares. Como questão final, o estudo inquiriu se haveria a necessidade de regulamentação específica para o exercício da atividade docente em serviço em seus cursos, à luz da integração ensino serviço; todos os participantes responderam sim. As seguintes sugestões foram trazidas pelos gestores: instituição de equipes específicas para conduzir a docência em serviço; constituição de plano de carreira específico para as ETSUS; implantação de quadro permanente por áreas; elaboração de legislação que ampare o trabalho docente realizado em serviço pelas ETSUS; e troca de experiências entre instituições com missão semelhante para encontrar soluções que desburocratizem a execução dos cursos.

\section{Discussão}

Utilizando-se do próprio trabalho como ferramenta metodológica para formar e qualificar trabalhadores com baixa escolarização, inseridos nos serviços de saúde e com grande conhecimen- 
to técnico advindo da prática cotidiana, as ETSUS tornaram-se um dos projetos mais bem sucedidos de profissionalização em larga escala na saúde na América Latina. O processo de consolidação destas instituições foi marcado por avanços e retrocessos ${ }^{23}$, principalmente por se distanciar do modelo formal de formação profissional no Brasil, que se mostrou ineficiente no contexto do SUS ${ }^{18,23}$.

A descentralização do poder decisório abriu oportunidades para maior participação cidadã e para inovações no campo da gestão pública dentro do contexto de reformas pós-ditadura, em que várias políticas públicas foram reinventadas e disseminadas pelo país, ${ }^{7,99-51}$. O compartilhamento de responsabilidades federativas e a descentralização das prerrogativas e competências institucionais entre as esferas governamentais produziram experiências singulares, como as ETSUS, que externam contradições primordiais entre as premissas constitucionais e normativas estabelecidas, as alternativas e opções de direcionalidade institucional, as condições de governabilidade e a capacidade efetiva dos governos de implementação das políticas e estratégias adota$\mathrm{das}^{52}$. As ETSUS se constituem para a administração pública brasileira a expressão da inovação na gestão, abrindo um horizonte novo no processo de educação institucional, que por seu caráter reflexivo contradiz normas e rotinas.

Fragilidades dos instrumentos de gestão das ETSUS são datadas desde a execução do PROFAE. Em 2004, a Universidade Estadual de Campinas (UNICAMP) publicou um relatório referente ao componente de modernização e fortalecimento das ETSUS, apontando medidas que poderiam contribuir com a sustentabilidade das escolas como a ampliação da autonomia de gestão (administrativa e financeira), um melhor posicionamento das ETSUS dentro da estrutura organizacional das secretarias estaduais de saúde, a regularidade de pagamento de docentes e a implementação de instrumento legal para contratação de professores, bem como para pagamento da hora/aula ${ }^{53}$.

O Ministério da Saúde vem apontando falhas na gestão dos projetos concebidos pela educação permanente como a necessidade de aperfeiçoamento e revisão dos processos administrativos e marcos legais por estados e municípios, de modo a permitir a contratação e a execução das ações educacionais em serviço ${ }^{26}$. A fragilidade gerencial relaciona-se a uma série de problemas jurídicos da administração pública brasileira, já que as secretarias de saúde não têm experiência em executar recursos com outras atividades que fogem dos modelos clássicos de licitação, muitas vezes ferindo as regras do controle e da administração pública ${ }^{26}$. Questões relacionadas à precariedade dos vínculos de trabalho no SUS e a alta mobilidade dos trabalhadores da saúde complicam a sustentabilidade administrativa da gestão da educação permanente ${ }^{33}$.

As debilidades na gestão da educação na saúde podem ser um indicativo de perda de relevância política da PNEPS no Brasil. Contudo, as limitações administrativas apresentadas pelas ETSUS refletem a própria gestão do SUS. Numa pesquisa realizada com 12 secretários estaduais de saúde, Lotufo e Miranda ${ }^{52}$ verificaram tensões em questões como burocracia, centralização administrativa, ausência de planos de carreira e ascensão funcional, salários baixos, problemas de governabilidade (pressão e interferências externas) e subfinanciamento. As secretarias que possuem Centros Formadores de Recursos Humanos e Escolas de Saúde Pública afirmaram ter capacidade limitada para dar conta dos enormes desafios de formação para o SUS no âmbito estadual $^{52}$. No mesmo sentido, Silveira et al. ${ }^{50}$ verificaram um quadro conhecido entre os trabalhadores do SUS: carência de estrutura adequada nas áreas de gestão do trabalho, educação, informação e comunicação em saúde; além de identificar as fragilidades da gestão por meio dos indicadores de apoio político.

Os gestores demonstraram neste estudo a necessidade de se regulamentar a atividade docente nos serviços de saúde, no que concerne a contratação e pagamento de professores, como forma de superar um obstáculo burocrático que interfere na atividade fim das escolas. Por um lado, a constituição de um quadro de trabalhadores permanente e estável que possa coordenar as atividades técnico-pedagógicas das ETSUS ao longo dos anos. Por outro, a institucionalização de instrumento jurídico que permita a contratação temporária dos docentes já empregados nos serviços de saúde para a realização dos cursos, fundamentados no caráter excepcional, temporário e relevante da formação de recursos humanos em saúde, considerando a legalidade da cumulação de vínculos pelos profissionais da saúde e da educação ${ }^{54}$, com a devida remuneração por todas as tarefas que a atividade docente exige do trabalhador, quer seja em classe ou fora ${ }^{55}$.

A regulação da integração entre educação e serviços de saúde foi abordada pela Organização Mundial da Saúde (OMS) no que concerne a ações inovadoras em formação de recursos hu- 
manos em saúde, com objetivo de promover condições satisfatórias para a qualificação das atuais e futuras equipes de saúde ${ }^{56}$. O governo brasileiro sinaliza a necessidade de regulação específica, por estados e municípios, do princípio da integração ensino serviço, referente ao magistério exercido por servidor público ${ }^{26}$. No entanto, o Ministério da Saúde pode ser pró-ativo nesta matéria, lançando bases técnicas e administrativas que sustentem no âmbito administrativo a educação permanente, baseado no artigo 200 da Constituição de 1988, que designa ao SUS o ordenamento da formação de recursos humanos na área da saúde ${ }^{57}$. O fortalecimento institucional das ETSUS no Brasil vai ao encontro do que Frenk et al. ${ }^{13}$ chamam de estabelecimento de um subsistema de educação nos sistemas de saúde, ou seja, sua auto-organização por meio de políticas públicas de formação de recursos humanos pelo próprio setor. Tal fato diminui a dependên- cia da macro estrutura liberal de produção de saúde, das práticas médico-centradas e também da estrutura educacional utilitarista, fortalecendo o trabalho visando o cuidado nos serviços públicos de saúde $\mathrm{s}^{10,13,15,16}$.

\section{Conclusão}

Após analisar aspectos gerenciais das Escolas Técnicas e dos Centros Formadores de Recursos Humanos do SUS, conclui-se que estas instituições apresentam problemas de gestão relacionados à integração ensino serviço. As ETSUS postulam a gestão do SUS uma nova dimensão do trabalho pela integração ensino serviço, sob a égide do regime jurídico único, que precisa ser disciplinada para conferir sustentabilidade às escolas do SUS, evitando dissensos com a legislação pública brasileira.

\section{Colaboradores}

FT Borges participou da concepção da pesquisa, da aplicação dos questionários da redação do artigo, nas versões preliminar e final. CAS Garbin e CE Siqueira orientaram a elaboração do texto, participaram da análise dos resultados e da redação da versão final do artigo. AJI Garbin e SAS Moimaz contribuíram com a análise crítica do artigo, bem como na redação. NB Rocha e LF Lolli participaram na coleta, tabulação dos dados e redação da versão preliminar do artigo.

\section{Agradecimentos}

A Coordenação de Aperfeiçoamento de Pessoal de Nível Superior (CAPES) pelo suporte ao projeto "Análise da organização do trabalho em instituições executoras da politica nacional de educação permanente em saúde no Brasil" com bolsa PDSE ao doutorando Fabiano Tonaco Borges; a mesma agência pela concessão de bolsa de doutorado aos co-autores Najara Barbosa da Rocha e Luíz Fernando Lolli. Ao Departamento de Gestão da Educação na Saúde do Ministério da Saúde do Brasil, pela disponibilidade de informações aos pesquisadores. A Escola de Saúde Pública do Estado de Mato Grosso (ESPMT) pela colaboração na aplicação dos questionários deste estudo. 
1. Báscolo E. Gobernanza y economía política de las políticas de APS en América Latina. Cien Saude Colet 2011; 16(6):2763-2772.

2. Ocké-Reis CO, Marmor TR. The Brazilian national health system: an unfulfilled promise? Int J Health Plann Manage 2010; 25(4):318-329.

3. Coelho IB. Democracia sem equidade: um balanço da reforma sanitária e dos dezenove anos de implantação do Sistema Único de Saúde no Brasil. Cien Saude Colet 2010; 15(1):171-183.

4. Paim J, Travassos C, Almeida C, Bahia L, Macinko J. The Brazilian health system: history, advances, and challenges. Lancet 2011; 377(9779):1778-1797.

5. Victora CG, Barreto ML, Leal MC, Monteiro CA, Schmidt MI, Paim J, Bastos FI, Almeida C, Bahia L, Travassos C, Reichenheim M, Barros FC. Health conditions and health-policy innovations in Brazil: the way forward. Lancet 2011; 377(9782):2042-2053.

6. Campos GWS. Reforma da Reforma repensando a saúde. $2^{\text {a }}$ Ed. São Paulo: Ed. Hucitec; 1997.

7. Paim JS. O que é o SUS. Rio de Janeiro: Editora Fiocruz; 2009.

8. Fleury S. Brazil's health-care reform: social movements and civil society. Lancet 2011;377(9779):17241725.

9. Fleury S, Ouverney ALM, Kronemberger TS, Zani FB. Governança local no sistema descentralizado de saúde no Brasil. Rev Panam Salud Publica 2010; 28(6):446-455.

10. Kilpatrick SI, Johns SS, Millar P, Le Q, Routley G. Skill shortages in health: innovative solutions using vocational education and training. Rural Remote Health 2007; 7(1):623-636.

11. Trotsky-Sirr R. Adentro Barrio Adentro: An American Medical Student in Venezuela. Social Medicine 2008; 3(4);248-252.

12. Tang KC, Nutbeam D, Kong L, Wang R, Yan J. Building capacity for health promotion - a case study from China. Health Promot Int 2005; 20(3):285-295.

13. Frenk J, Chen L, Bhutta ZA, Cohen J, Crisp N, Evans T, Fineberg H, Garcia P, Ke Y, Kelley P, Kistnasamy B, Meleis A, Naylor D, Pablos-Mendez A, Reddy S, Scrimshaw S, Sepulveda J, Serwadda D, Zurayk H. Health professionals for a new century: transforming education to strengthen health syste$\mathrm{ms}$ in an interdependent world. Lancet 2010; 376(9756):1923-1958.

14. Ceccim RB, Feuerwerker LCM. O quadrilátero da formação para a área da saúde: ensino, gestão, atenção e controle social. Physis Rev Saúde Coletiva 2004; 14(1):41-65.

15. Cohen JJ. Medical Education in an Era of HealthCare Reform. Perspect Biol Med 2011; 54(1):61-67.
16. Rieselbach RE, Crouse BJ, Frohna JG. Teaching Primary Care in Community Health Centers: Addressing the Workforce Crisis for the Underserved. Ann Intern Med 2010; 19; 152(2):118-122.

17. Campos AI. Nuevo profesionalismo, educación médica y sistemas de salud. Cien Saude Colet 2011; 16(6):2725-2732.

18. Sório RER. Educação profissional em saúde no Brasil: a proposta das Escolas Técnicas de Saúde do Sistema Único de Saúde. Formação 2002; 2(5):45-57.

19. Waitzkin H, Iriart C, Estrada A, Lamadrid S. Social medicine then and now: Lessons from Latin America. Am J Public Health 2001; 91(10);1592-1601.

20. Tajer D. Latin American Social Medicine: Roots, Development During the 1990s, and Current Challenges. Am J Public Health 2003: 93(12):2023-2027.

21. Freire P. Pedagogia do oprimido. 47 a ed. Rio de Janeiro: Paz e Terra; 2005.

22. Foucault M. Microfísica do poder. Rio de Janeiro: Graal; 1985.

23. Santos I. Escolas Técnicas de Saúde do Sistema Único de Saúde (ETSUS). Formação 2002; 2(5):8795.

24. Galvao E. Cenário nacional das escolas técnicas do SUS: a criação dos CEFOR no Brasil. Saude soc. 2009; 18(Supl.2):60-63.

25. Brasil. Ministério da Saúde (MS). Portaria no 2.970, de 25 de novembro de 2009 que Institui a Rede de Escolas Técnicas do SUS e dispõe sobre as diretrizes para a sua organização. Diário Oficial da União 2009; 26 nov.

26. Fundação Oswaldo Cruz (Fiocruz). Um balanço da política Nacional de Educação Permanente em Saúde. Revista RET-SUS 2010; 5(38):12-16.

27. Brasil. Ministério do Planejamento, Orçamento e Gestão (MPOG). Instituto Brasileiro de Geografia e Estatística (IBGE). Estatística de Saúde Assistência Médico Sanitária [serial on the internet] 2010 [cited 2011 jan 22]; [about 167 p.]. Available from: http://www.ibge.gov.br/home/estatistica/populacao /condicaodevida/ams/2009/ams2009.pdf

28. Pereira IB, Ramos MN. Breve histórico das instituições. Educação profissional em saúde [monografia]. Rio de Janeiro: Fiocruz; 2006.

29. Sório R, Lamarca I. Novos desafios das escolas técnicas de saúde do SUS. Physis 1998; 8(2):147-164.

30. Fundação Oswaldo Cruz (Fiocruz). Entrevista Izabel Santos. Revista RET-SUS 2010; 5(39):4-7.

31. Fundação Oswaldo Cruz (Fiocruz). Antes da Rede. Revista RET-SUS 2011; 5(41):5-6.

32. Souza MAS, Galvão EA, Dos Santos I, Roschke MA. Processo educativo nos serviços de saúde. Brasília: Organização Pan-americana da Saúde (OPAS); 1991. (Série desenvolvimento de recursos humanos ${ }^{\circ} 1$ ) 
33. Davini MC, Nervi L, Roschke MA. La Capacitación del Personal de Los Serviços de Salud en Proyectos Relacionados con los Processos de Reforma Sectorial. Programa de Desarrollo de recursos Humanos. Washington: Organização Pan-americana da Saúde (OPAS); 2002.

34. Brasil. Ministério da Saúde (MS). Secretaria de Gestão do Trabalho e da Educação na Saúde. (Comunicação Pessoal dez 20 2010).

35. Brasil. Ministério da Saúde (MS). Portaria no 1298 , de 28 de novembro de 2000 que Institui a Rede de Escolas Técnicas e Centros Formadores vinculados às instâncias gestoras do Sistema Único de Saúde (RET-SUS). Diário Oficial da União 2000; 28 nov.

36. Fundação Oswaldo Cruz (Fiocruz). PROFAPS. Revista RET-SUS 2010; 5(38):10-15.

37. Fundação Oswaldo Cruz (Fiocruz). RETSUS participa de formação de profissionais no Haiti. Revista RET-SUS 2010; 5(39):2-5.

38. Ramos M. Concepções e práticas pedagógicas nas escolas técnicas do Sistema Único de Saúde: fundamentos e contradições. Trab. educ. Saúde 2009; 7(Supl.1):153-173.

39. Berbel NAN. A problematização e a aprendizagem baseada em problemas: diferentes termos ou diferentes caminhos? Interface Comun Saúde Educ 1998; 2(2):139-154.

40. Lobo Neto FJS. Ser professor: necessidade de formação professional específica. Formação 2002; 4(1): 5-13.

41. Bomfim MIRM, Torrez MNFB. A formação do formador no PROFAE: refletindo sobre a proposta na área de enfermagem. Formação 2002; 4(1):15-34.

42. Marques CMS. Certificação de competências profissionais: o que o PROFAE está pensando e fazendo. Formação 2001; 2(1):55-62.

43. Torrez MNFB. Sistema de Certificação de Competências PROFAE: bases conceituais. Formação 2001; 2(1):47-53.

44. Brasil. Ministério da Saúde. Portaria $n^{0} 198$, de 13 de fevereiro de 2004 que Institui a Política Nacional de Educação Permanente em Saúde como estratégia do Sistema Único de Saúde para a formação e o desenvolvimento de trabalhadores para o setor e dá outras providências. Diário Oficial da União 2004; 16 de fev.

45. Brasil. Ministério da Saúde. Portaria ${ }^{0} 1996$, de 20 de agosto de 2007 que Dispõe sobre as diretrizes para a implementação da Política Nacional de Educação Permanente em Saúde e dá outras providências. Diário Oficial da União 2007; 20 de ago.

46. Cecilio LCO. Colegiados de gestão em serviços de saúde: um estudo empírico. Cad Saude Publica 2010; 26(3):557-566.
47. Maxwell JA. Qualitative research design: An interactive approach. $2^{\text {a }}$ Ed. London: Sage; 2005.

48. Minayo MCS, Sanches O. Quantitativo-qualitativo: oposição ou complementaridade? Cad Saude Publica 1993; 9(3):237-248.

49. Abrucio FL. Trajetória recente da gestão pública brasileira: um balanço crítico e a renovação da agenda de reformas. Rev Adm Pública 2007; 41(N.Esp):67-86

50. Silveira DS, Facchini LA, Siqueira FV, Piccini RX, Tomasi E, Thumé E, Silva SM, Dilélio AS, Maia MFS. Gestão do trabalho, da educação, da informação e comunicação na atenção básica à saúde de municípios das regiões Sul e Nordeste do Brasil. Cad Saude Publica 2010; 26(9):1714-1726.

51. Fadel CB, Schinider L, Moimaz SAS, Saliba NA. Administração pública: o pacto pela saúde como uma nova estratégia de racionalização das ações e serviços em saúde no Brasil. Rev Adm Pública 2009; 43(2):445-456.

52. Lotufo M, Miranda AS. Sistemas de direção e práticas de gestão governamental em secretarias estaduais de Saúde. Rev Adm Pública 2007; 41(6);1143-1163.

53. Universidade Estadual de Campinas (Unicamp). Avaliação institucional do PROFAE e definição de parâmetros para o estabelecimento de sistemas de acompanhamento do mercado de trabalho em saúde, especialmente em enfermagem. Campinas: Unicamp; 2004.

54. Brasil. Artigo 37 da Constituição da Republica Federativa do Brasil de 1988. Diário Oficial da União 1988; 5 out.

55. Brasil. Lei no 9.394, de 20 de dezembro de 1996. Estabelece as diretrizes e bases da educação nacional. Diário Oficial da União 1996; $23 \mathrm{dez}$

56. World Health Organization (WHO). Framework for Action on Interprofessional Education \& Collaborative Practice. Geneva: World Health Organization (WHO); 2010.

57. Brasil. Artigo 200 da Constituição da Republica Federativa do Brasil de 1988. Diário Oficial da União 1988; 5 out.

Apresentado em 16/05/2011

Aprovado em 30/06/2011

Versão final apresentada em 10/08/2011 